\title{
On the Golgi apparatus, Alkaline Phosphatase and Protein of Liver Cells of a Fish (Oryzias latipes) during Starvation \\ II. On Alkaline Phosphatase
}

By

\section{Sakae Iwasaki}

Department of Anatomy, School of Medicine, Keio-Gijuku University, Tokyo

Since Takamatsu (1939) and Gomori (1939) found quite independently the histochemical technique for the demonstration of alkaline phosphatase, a great number of studies on phosphatase activity of normal and pathological organs have been reported by many authors. Phosphatase is, as generally believed, associated with the metabolism of sugar, fat, lipid and nucleoprotein, and therefore it may be probable that the phosphatase activity of various organs changes its intensity during starvation.

Mawatari and Ju (1942), Deane and Dempsey (1945), Wachstein (1945) and Arizono (1950) reported on this problem. Among these authors, Mawatari and $\mathrm{Ju}, \mathrm{Wach}$ stein and Arizono described the changes of phosphatase in liver of starved animals, all belonging to mammalia. I observed the changes of alkaline phosphatase activity during starvation in liver of an osseous fish, which can endure comparatively long duration of starvation.

\section{Material and Methode}

Individuals of an osseous fish (Oryzias latipes), all members of which had been well fed previously, were divided into two groups. One group was kept in distilled water without receiving any food, changing the water every three days. Another group was kept in usual manner as the control receiving sufficient food. The starvation experiment was started on 10. April 1951 and continued for the following thirty days. The temperature of the water was approximately 
$20^{\circ} \mathrm{C}$. throughout this period. On the tenth, the twentieth and the thirtieth day liver was excised for the living fish and was fixed with cold aceton as soon as possible. For the demonstration of alkaline phosphatase the Gomori's revised method (1946) was applied.

\section{Observations}

Control :

In the liver of Oryzias latipes, alkaline phosphatase shows its strongest activity on vessel wall. In the liver cell, nucleolus gives the strongest activity, a little weaker than vessel wall. Nuclear membrane has also strong activity next to nucleolus, although weaker than nucleolus. Caryoplasm gives obvious positive reaction of the enzyme as a whole, and contains in itself a network composed of fine threads, which shows stronger reaction than the adjacent caryoplasm. Cytoplasm is uniformly positive of this reaction and sometimes more strongly positive on the side neighbouring blood vessel than the other. Within cytoplasm threadlike matters are often seen, which give more intense reaction of the enzyme than the adjacent cytoplasm. These are not so clearly stained out as those which are demonstrated by means of the acid phosphatase detection procedure, in kidney and liver cells of rat and rabbit by Goetsch and Reynolds (1951) and in the liver cells of Oryzias latipes by Tsukuda (1952b), and which are considered as corresponding to mitochondria. These threadlike matters which are positive of alkaline phosphatase, however, may be probably considered to be mitochondria. "Special Granules" (Tsu kuda, 1952a) give no positive reaction. The bile capillary among liver cells shows fairly stronger activity (Fig. 3). The intensity of alkaline phosphatase activity differs among individual cells, but no evident difference of the intensity is present between the cells from the different parts of liver. No difference among individual fishes is also found.

Ten days starvation:

Generally seen, alkaline phosphatase is yet slightly increased, on vessel wall and nucleolus there occurs a particular intensification of the enzyme activity. The picture of the network, which was clearly seen in the control cases, becomes obscure being covered by the universal intensification of the activity of caryoplasm. The activity on cytoplasm is slightly increased than the control, and the reaction of the threadlike bodies are also somewhat intensified. Bile capillary gives stronger activity than the control. The increase of the intensity 
of alkaline phosphatase activity of liver cells caused by the ten days starvation is less obvious than that of acid phosphatase (Tsukuda, 1952) (Fig. 2).

Twenty days starvation:

Comparing with the findings in the control group, a certain reduction in phosphatase activity is generally recognized. A particular decrease of the activity is seen on blood vessel wall and nucleolus, more marked than other parts. The activity on nuclear membrane and nucleus reduces to some extent, and the network within nucleus is slightly visible. The activity on bile capillary is also diminished (Fig. 3).

Thirty days starvation:

The size of cells become cosiderably smaller, and general bss of the enzyme activity is extremely obvious. The activity of blood vessel wall and nucleolus decreases especially markedly. The enzyme activity of nuclear membrane and nucleus also dimishes, and the intranuclear network is hardly visible. The activity of cytoplasm, although it is weakened, retains its intensity more than other parts of a cell, showing the same intensity as that of nucleus, and the threadlike bodies may not be recognized. Bile capillary reacts no more (Fig. 4).

Such changes of alkaline phosphatase activity always occur uniformly in every part of liver, and their difference between fish individuals can hardly be proved.

Ju (1945), examining phosphatase activity of fish ti:sues in normal conditions (Plecoglossus altvelis, Parasilurus asotus, Carassius auratus, Trichiurus japonicus and Limanda augustirostris), described that in fish liver cell and blood capillary showed a positive alkaline phosphatase reaction only extremely rarely. Against his results, my findings from the observation on the liver of Oryzias latipes of normal condition in control cases demonstrate a positive enzyme activity on blood vessel wall, liver cells and bile capillary of every individual fish.

Mawatari and $\mathrm{Ju}$ (1942) reported the results of their observation of phosphatase activity of Cetellus dauricus during hibernation. They found that a considerably intense phosphatase activity is present on liver cells in the central part of lobule of liver and in the interzone and Kupfer cells, despite the lack of a distinct activity of the enzyme on liver in its normal condition.

Wachstein (1945), observing alkaline phosphatase activity of mice and rats after starvation for a period of seven days, found that in mice cytoplasmic phosphatase activity on bile capillary and blood vessel 
wall shows sometimes an intensification without regard to the length of the duration of starvation, while in rats, on the other hand, a slight or no change may be proved.

According to Arizono's 72 hours starvation experiment (1950) in mice, cytoplasmic and nuclear alkaline phosphatase of liver increases its activity slightly with the duration of starvation, the enzyme activity on endothelium of sinusoid intensifies greatly from 12 hours to 48 hours after the start of starvation, then diminishes gradually again, and at last disappears in 72 hours. From my findings in liver of Oryzias latipes it may be noticed that alkaline phosphatase activity shows a slight temporary intensification and then diminishes again with the progress of starvation. Moreover, both the increase and the decrease of alkaline phosphatase activity is more prominent on blood vessel wall and nucleolus than other parts, and on the other hand, cytoplasm shows the smallest fluctuation.

\section{Summary}

1. The alkaline phosphatase activity on liver of an osseous fish (Oryzias latipes) was observed after ten, twenty and thirty days starvation.

2. In the case of ten days starvation the alkaline phosphatase activity increases on every parts of liver slightly and thereafter decreases gradually.

3. The increase or the decrease of the alkaline phosphatase activity is prominent on blood vessel wall and nucleolus, and only slight on cytoplasm.

This study was carried out with the aid of The Subsidy Fund for Science Promotion from Keio.Gijuku given to Astist. Prof. M. Ihnuma.

\section{References}

Arizo no, H. 1950 Hisochemical studies on the tissue phosphatases during the starvation. Osaka-Daigaku-Igaku-Zasshi vol. 2 p.359

Deane, H. W. and Dempsey, E. W. 1945 The localization of phosphatase in the Golgi region of intestioral and other opithelial cells. Anat. Rec. vol. 93 p. 401

Goetsch, T.B. and P. M. Reynolds. 1951 Obtaing uniform resultes in the histochemical technic for acid phosphatase. Stain Tech, vol. 26

Gomori, G. 1939 Microchemical demonstration of phosphatase in tissue sections. Proc. Soc. Exp. Biol. \& Med. vol. 42 p. 23

Gomori, G. 1946 from D. Glick 1949 Techniques of Histo-and Cytochemistry. 
Schu-Hoschun 1945 A Study of phosphatase reaction on fish. Manshu-Igaku-Zasshi vol. 42 p. 109

Maw a tari, H. und Ju-F. 1942 Uber die histochemische Phosphatasereaktion bei Feldeichhörnchen der Mandschurei in der Winterschlafszeit. Trans. Soc. Path. Jap. vol. 33 p. 77

Takamatsu, H. 1939 Histological and biochemical studies of phosphatase. Trans. Soc. Path. Jap. vol. 29 p. 492

Tsukada, T. 1952a On the Mitochondria, Ribonucleic Acid, Acid Phosphatase and Polysacchatide of Liver Cells of a Fish (Oryzias latipes) during Starvation. I. On the Mitochondria and Ribonucleic Acid. Fol. Anat. Jap. Bd. 24 s. 41

Tsukada, T. 1952b On the Mitochondria, Ribonucleic Acid, Acid Phosphatase and Poly. saccharide of Liver Cells of a Fish (Oryzias latipes) during Starvation. Fol. Anat. Jap. Bd. 24 S. 103

Wachstein, M. 1945 Influence of dietary deficiencies and various poisons of the histochemical distribution of phosphatase in the liver. Arch. path. vol. 40 p. 57

\section{Explanation of figures}

Fig. 1 control

Fig. 210 days starvation

Fig. 320 days starvation

Fig. 330 days starvation magnification ca $4000 x$ 

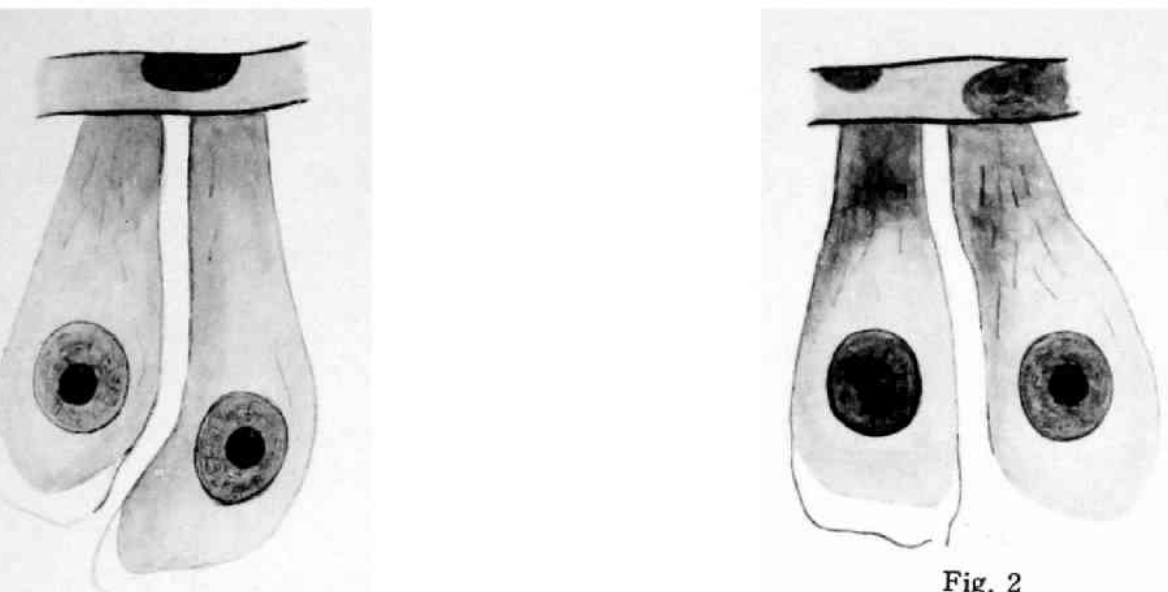

Fig. 2

Fig. 1

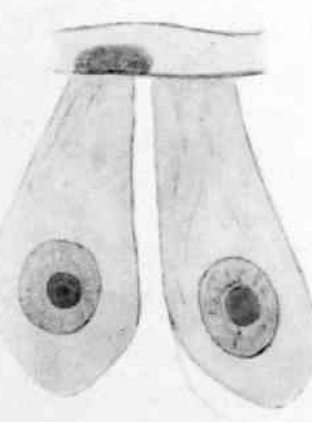

Fig. 3

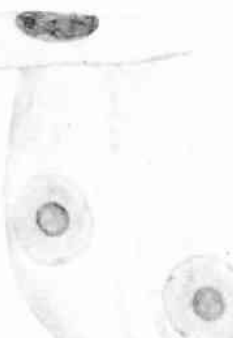

Fig. 4 